\title{
Publisher's Note: DFT+DMFT study on soft moment magnetism and covalent bonding in $\mathrm{SrRu}_{2} \mathrm{O}_{6}$ [Phys. Rev. B 96, 155135 (2017)]
}

Atsushi Hariki, Andreas Hausoel, Giorgio Sangiovanni, and Jan Kuneš

(Received 1 December 2017; published 7 December 2017)

DOI: 10.1103/PhysRevB.96.239901

This paper was published online on 24 October 2017 with typographical errors in the compounds that appear in the abstract. All instances of " $\mathrm{SrRu}_{2} \mathrm{O}_{3}$ " should read as " $\mathrm{SrRu}_{2} \mathrm{O}_{6}$." The abstract has been corrected as of 1 December 2017 . The abstract is incorrect in the printed version of the journal. 